\title{
El innovador rol del mediador en el proceso concursal. La gestión cooperativa de la insolvencia
}

\author{
The innovative role of the mediator in bankruptcy procedures. \\ Cooperative management of insolvency
}

\author{
María José Briz Clariget ${ }^{1}$ \\ ORCID: 0000-0002-7620-8073 \\ Daniel Martínez Vigil Cibils² \\ ORCID: 0000-0002-1105-1706 \\ Florencia Rychtenberg Milans ${ }^{3}$ \\ ORCID: 0000-0003-4133-4034 \\ ${ }^{13}$ Universidad Católica del Uruguay. \\ ${ }^{2}$ Universidad de Montevideo, Uruguay. \\ Correos: mbriz@ucu.edu.uy; danielmartinezvigil@gmail.com; frychten@gmail.com
}

Recibido: 25/09/2020

Aceptado: 27/10/2020

Resumen: El artículo se centra en el análisis del rol del mediador en el proceso concursal y en las ventajas que este método tiene tanto para el deudor como para los acreedores. Se realiza un abordaje descriptivo y analítico, que presenta la mediación como herramienta de gestión de conflictos, teniendo en cuenta la experiencia internacional y la situación en Uruguay, donde se presentó un proyecto de ley que procura modificar la Ley Concursal y crear la figura del mediador en los procesos concursales. Se concluye que el derecho concursal uruguayo necesita actualizar su normativa legal y adoptar soluciones no adversariales como la mediación, que son tendencia mundial.

Palabras clave: mediación concursal; mediador concursal; procesos concursales; mediación; resolución alternativa de conflictos; soluciones no adversariales.

\begin{abstract}
The article focuses on the analysis of the role of the mediator in the bankruptcy procedure and the advantages that this method has for both the debtor and the creditors. A descriptive and analytical approach is made, which presents mediation as a tool for conflict management, taking into account the international experience and the situation in Uruguay, where a bill was presented to modify the Bankruptcy Law and to create the figure of the mediator in the bankruptcy proceedings. It is concluded that Uruguayan bankruptcy law needs to update its legal regulations and adopt non-adversarial solutions such as mediation, which are a worldwide trend.
\end{abstract}

Keywords: bankruptcy mediation; bankruptcy mediator; bankruptcy procedures; mediation; alternative dispute resolution; non-adversarial solutions. 


\section{Introducción}

La ley de Declaración Judicial de Concurso y Reorganización Empresarial, Ley 18.387 (en adelante, la Ley o Ley Concursal) es la única fuente formal en Uruguay que rige en materia de concursos empresariales. En esta se establecen los supuestos que habilitan el ingreso al concurso, procedimientos y requisitos para la presentación de los acreedores, así como los términos y condiciones para llegar a un acuerdo judicial y permitir el fin último de la ley que es la continuidad de la empresa, siempre y cuando sea viable.

La aplicación del proceso concursal como único mecanismo para resolver los conflictos de la insolvencia empresarial ha cercenado la posibilidad de explorar otras opciones que podrían obtener mejores resultados.

Dada la situación en la que se encuentra el mundo hoy, podemos concluir que a nivel internacional el concurso ha pasado a ser una situación normal en el ciclo vital de los agentes económicos, frente a períodos anteriores a este tipo de crisis en los que era más raro que se diera (muchos menos deudores concursados). Ello ha obligado a los países a buscar soluciones que permitan encontrar un equilibrio entre los intereses de los acreedores, de los deudores (gran parte de los cuales ven afectado no solo su patrimonio y futuro profesional o empresarial, sino, incluso, el personal, lo que los enfrenta a un manifiesto riesgo de exclusión social) y del sistema económico en su conjunto (para el que resulta fundamental salvar y estimular el tejido empresarial, seriamente dañado en estos últimos años) (Sánchez, 2018).

El ofrecimiento por parte del legislador de un nuevo modelo de resolución de situaciones de crisis empresariales o de insolvencia con menores costes y con plazos determinados, junto a la posible extinción de las deudas, puede llevar a los potenciales emprendedores de actividades empresariales a arriesgarse en el inicio de una actividad de este tipo. El resultado final es la ampliación e impulso de la red empresarial a nivel estatal con un impacto indirecto en la mejora de la situación económica.

En derecho comparado, la mediación mercantil o mediación concursal no es novedosa, sino que se viene aplicando hace más de diez años, lo que permite evitar los significativos costos de los procesos judiciales y honorarios de profesionales, acortar plazos y preservar la reputación de la empresa que transita una situación de insolvencia en el marco de la confidencialidad. Esto habilita a las partes a negociar sin la obligación 
de ajustarse a una propuesta de pago específica; así se obtienen resultados más favorables para todos los involucrados y se preservan las relaciones comerciales.

En este sentido, el derecho concursal uruguayo tiene la urgente necesidad de actualizarse: debe atender a las carencias que plantea su normativa legal y comenzar a adoptar las tendencias mundiales mediante la aplicación de soluciones no adversariales como la mediación.

En esta línea, se presentó en el mes de julio de 2020 un proyecto de ley — que se encuentra a estudio - a los efectos de modificar ciertas disposiciones de la Ley Concursal, como crear la figura del mediador concursal, establecer sus funciones, facultades, objetivos e incompatibilidades, así como, también, otorgar una moratoria provisional al deudor durante los plazos de negociación con sus acreedores.

Este artículo tiene como objetivo fundamentar la relevancia de la inclusión de la figura del mediador a nivel legal en el proceso concursal. Se analizará el impacto de la gestión constructiva, cristalizada en su participación en la celebración de un acuerdo entre el deudor y sus acreedores con la finalidad de satisfacer las necesidades de todos los que participan en el proceso.

\section{La gestión alternativa de conflictos en el ámbito comercial}

La implementación de gestión de conflictos en diferentes ámbitos es una tendencia a nivel internacional. El ámbito comercial no está ajeno a ello y es por eso que los métodos de gestión alternativa de conflictos vienen ganando terreno como vías efectivas en la solución de conflictos e, incluso, como forma de prevenirlos. Es práctica habitual hoy en día la inclusión de cláusulas en contratos comerciales que dejan previsto este método de resolución como la primera alternativa a la hora de gestionar posibles incumplimientos.

La empresa, como unidad económica-social, cumple un rol fundamental en dicho ámbito. Aquella se encuentra integrada por elementos de diferente índole - humanos, materiales, tecnológicos - que tienen como finalidad interactuar entre sí a los efectos de obtener rentabilidad a través de su intervención en el mercado de bienes y servicios (Dueñas, 2017).

En dicho mercado, la empresa establece múltiples relaciones jurídicas con otros actores y es posible que en algunas de ellas se presenten conflictos. Estos pueden ocurrir tanto en el ámbito público como en el privado, dependiendo de con quién establezca relación la empresa. En este trabajo nos centraremos exclusivamente en los conflictos que 
se presentan en el ámbito privado y que podrían gestionarse a través de un proceso concursal.

Los conflictos diarios a los que se enfrenta una empresa tienen un alto costo tanto económico como humano, ya que muchas veces se presentan con partes externas a la empresa y terminan afectando su funcionamiento interno.

Por otro lado, el conflicto genera una evidente pérdida de oportunidad, ya que la empresa debe utilizar muchos recursos para gestionarlo y pierde la posibilidad de aplicarlos al proceso productivo, sea cual sea el rubro, y generar rentabilidad.

Una empresa en situación de insolvencia, normalmente, carece de recursos suficientes para gestionar el conflicto de una manera efectiva. Habitualmente, dicha gestión queda en manos de operadores del derecho que pretenden resolver los conflictos a través del sistema judicial. Es aquí donde la gestión se enfrenta a un proceso rígido, costoso y lento, pues el sistema de resolución no responde a las necesidades de la empresa, daña su reputación e, incluso, impacta directamente sobre su rentabilidad, lo que determina que, la mayoría de las veces, la empresa ingrese en liquidación.

Es en este escenario, dentro del ámbito comercial, donde los medios alternativos, complementarios o ágiles ${ }^{1}$ de resolución de conflictos ganan espacio y se desarrollan a pasos agigantados a nivel internacional. En el ámbito comercial los más utilizados son la negociación, la mediación y el arbitraje.

La negociación es la gestión del conflicto por cada una de las partes directamente. La mediación, básicamente y sin perjuicio del desarrollo que haremos del tema - ya que es el objeto de análisis de este trabajo - es la gestión del conflicto a través de un proceso en el que participa un tercero imparcial que ayuda a las partes a abordarlo. El arbitraje, en tanto, es un proceso del que también participa un tercero que tiene la facultad de decidir por las partes e imponer soluciones dentro de determinadas pautas que están reguladas legalmente. Según Gonzalo Boronat y David Ruiz (2017):

La mediación se diferencia del arbitraje en tres aspectos fundamentales, el primero, en la sumisión a un tercero por las partes; en este caso, al árbitro o al tribunal arbitral que las partes designan. Este hecho se da, pues es el

\footnotetext{
${ }^{1}$ La forma de denominarlos ha ido cambiando con el correr del tiempo. El concepto alternativo se refiere al proceso judicial, pero en la actualidad ha perdido sentido, ya que se considera complementario a este. El concepto ágil viene relacionado a su rapidez en cuanto a la gestión, y son muchos los contratos que hoy en día prevén la gestión de conflictos bajo la denominación de métodos ágiles.
} 
árbitro designado por las partes el que emitirá un laudo (decreto asimilable a una resolución) que determinará lo que ambas partes están obligadas a cumplir. La mediación ofrece una solución distinta, pues son las propias partes las que acuerdan una solución pactada en su conflicto, y tras la labor del mediador, que es quien conduce la dinámica del acuerdo, se supervisa la legalidad del cumplimiento (incluso por un tercero, distinto a las partes y el mediador).

El segundo aspecto fundamental es el dominio del objeto del proceso. [...] En el arbitraje se establecen limitaciones en el proceso, así como la sumisión impide la negociación directa entre partes en muchas ocasiones. En la mediación, las partes pueden incorporar, reducir, ampliar, cambiar y modificar con total libertad el objeto y los términos del acuerdo en todo momento, por ende, es un sistema mucho más versátil y maleable.

En tercer lugar, la mediación reduce especialmente los costes frente a los demás sistemas de resolución de conflictos, y los reduce en dos vías, en los costes directos y en los indirectos. (pp. 25 -26.)

Los métodos reseñados, tanto a nivel nacional como internacional, son guiados por principios tales como la autonomía de la voluntad, la tutela de la empresa y su conservación, la prevención, no agravamiento y solución de conflictos mediante reglas de desbloqueo y cláusulas sobre medios alternativos de gestión.

\section{La gestión de conflictos en el proceso concursal}

En el marco de los conflictos dentro del derecho comercial nos centraremos en aquellos que se presentan en el proceso concursal y, en especial, en el rol del mediador en dicho proceso. En este sentido, corresponde analizar brevemente las características del referido trámite para poder comprender el tipo de conflictos que en él se presentan y que deben ser gestionados.

\section{El proceso concursal}

El proceso concursal es un trámite judicial al que recurre un deudor que atraviesa dificultades económicas o de liquidez tales que le impiden el puntual y regular cumplimiento de sus obligaciones. 
El presupuesto objetivo para la declaración del concurso es la insolvencia, definida por la Ley 18.387 como el estado en que se encuentra un deudor que no puede cumplir con sus obligaciones. Tal previsión ha sido entendida por Camilo Martínez Blanco (2018, pp. 160 - 162) como la imposibilidad de un deudor de hacer frente a sus obligaciones inmediatamente exigibles con sus medios regulares de pago.

En estas circunstancias, la ley establece al deudor un plazo de treinta días desde que conoció, o debió haber conocido, su estado de insolvencia, para que se presente a solicitar su concurso bajo el riesgo de poder ser responsabilizado personalmente de las deudas contraídas en una eventual calificación culpable del concurso.

En forma previa a la declaración de concurso, el deudor puede presentar a sus acreedores una propuesta de pago conocida como acuerdo privado de reorganización. Una vez declarado el concurso, las opciones para poner fin a este estado de insolvencia son las siguientes: homologar un convenio alcanzado en la junta de acreedores o, de manera extrajudicial, fuera de ella - lo que posibilitaría la continuidad de la empresao la liquidación de esta, por lo que se procede a su venta en bloque o en partes.

Como vemos, la declaración judicial de concurso de una empresa no implica, necesariamente, la liquidación de sus bienes como primera alternativa y, por ende, su clausura. Por el contrario, la propia Ley busca en primera instancia la conservación de la empresa, siempre y cuando esta sea viable, por lo que ordena, en primer lugar, la tramitación de la etapa de convenio e incentiva al concursado a lograr un acuerdo con sus acreedores (Olivera, 2008, p. 26). Esta solución — la continuación de la empresa - se considera preferible a una eventual liquidación porque tutela en mejor forma el interés de todos los acreedores y del propio deudor, que podrá mantener en actividad la empresa si es viable- y, por tanto, seguir generando activos para salir de la situación de insolvencia, lo que claramente es positivo para los acreedores, quienes podrán ver satisfechos sus créditos.

La estadística demuestra que las empresas que logran alcanzar un acuerdo con sus acreedores no superan el $10 \%$ de las concursadas. Las restantes, necesariamente resultan liquidadas, lo que demuestra que las soluciones legalmente previstas no son efectivas. En adición, el concurso continúa siendo un estigma para las deudoras, que no recurren tempestivamente al instituto por temor a dañar su imagen. Ante la falta de entendimiento de las partes se perjudican las relaciones comerciales, lo que atenta contra la posibilidad 
de alcanzar soluciones consensuadas, ya que la única posibilidad de acordar es adhiriendo a una propuesta unilateral del deudor, sin una instancia de negociación.

En definitiva, los acreedores pierden la fe en un proceso que sigue resultando largo, costoso, engorroso y que no les permite la satisfacción de sus créditos. La continuidad de la empresa queda determinada por el voto de un acreedor resignado y descreído, poco motivado a prestar una segunda oportunidad a su deudor. Es por ello que resulta necesario recurrir a un método de resolución alternativa de conflictos que permita asegurar un resultado más favorable para todas las partes intervinientes.

\section{La mediación como herramienta de gestión de conflictos en el proceso concursal}

\section{Concepto}

La mediación, en la actualidad, cuenta con muchas definiciones que varían de acuerdo con las diferentes concepciones que el término ha adoptado a lo largo de su evolución.

Jay Folberg y Alison Taylor (1997) entienden a la mediación como:

El proceso mediante el cual los participantes, con la asistencia de una persona o personas neutrales, aíslan sistemáticamente los problemas en disputa con el objeto de encontrar opciones, considerar alternativas y llegar a un acuerdo mutuo que se ajuste a sus necesidades. (Citado en Balletto, Briz y Falca, 2015, p. 85.)

Elena Highton (2004), por su parte, establece que es:

Un procedimiento no adversarial en el cual un tercero neutral ayuda a las partes a negociar para llegar a un resultado mutuamente aceptable. Constituye un esfuerzo estructurado para facilitar la comunicación entre los contrarios, con lo que las partes pueden voluntariamente evitar el sometimiento a un largo proceso judicial — con el desgaste económico y emocional que este conlleva - pudiendo acordar una solución para su problema en forma rápida, económica y cordial. (p. 122.)

Por lo tanto, de estas acepciones entendemos que la mediación es un procedimiento no adversarial mediante el cual las partes, asistidas por un mediador — que 
constituye un tercero imparcial—, a través de la comunicación, aíslan los problemas y tratan de obtener opciones o alternativas para llegar a un acuerdo que se ajuste a las necesidades de ambas partes, evitando un desgaste económico y emocional como el que conlleva un proceso judicial.

Durante el proceso, el mediador tiene como finalidad facilitar que las partes logren una eficiente comunicación que les permita encontrar la vía para resolver el conflicto, escucharse uno al otro, explorar soluciones y transitar juntos, de manera constructiva, hacia el futuro, en busca de una solución que satisfaga los intereses de todos los involucrados. En el ámbito del proceso concursal será viable recurrir a esta herramienta siempre y cuando exista la voluntad de todas las partes involucradas de someterse a dicho instituto.

En cuanto a la conveniencia de la mediación en el proceso concursal y, sobre todo, con respecto al proceso judicial, no existe unanimidad en cuanto a la doctrina. Michele Taruffo (2011) afirma que, si bien el proceso judicial es considerado como una instancia, las partes se enfrentan, y ese enfrentamiento se realiza en un marco donde estas «poseen la oportunidad de dar sus razones con precisión, hacer que las mismas consten fehacientemente, en condiciones de defensa que permiten garantizar normalmente la igualdad de las armas» (p. 22).

Jordi Nieva Fenoll manifiesta que la parte comparece en la mediación en solitario y que, además, en el proceso judicial está acompañada de su abogado, que se encuentra en el mismo nivel de formación que el juez, que es quien decide. Este hecho asegurará la calidad del debate y se garantizará que ambas partes estén en pie de igualdad en esta línea (Fenoll, 2014, pp. 733 - 736). En Uruguay, este argumento no tiene cabida, ya que, de acuerdo a lo previsto legalmente, la parte debe acudir al proceso de mediación con asistencia letrada obligatoria, por lo tanto, la calidad de sus argumentos está garantizada. ${ }^{2}$

\section{Características}

La mediación es un proceso confidencial: toda la información que de este pudiera surgir debe manejarse por las partes y el mediador de manera reservada y no puede ser utilizada con fines ajenos al propio proceso.

\footnotetext{
${ }^{2}$ Código General del Proceso. Ley Procesal Civil 16.995, artículo 2.
} 
En cuanto a la característica de la neutralidad, como esencial en el rol del mediador, Mauro Bove $(2011,125$ - 158) considera casi imposible que el mediador, directa o indirectamente, no termine formulando una propuesta de acuerdo, sobre todo, como herramienta cuando el proceso pueda quedar estancado. Se considera que este tipo de propuestas se pueden generar en procesos de mediación debido a que, mediante la utilización de técnicas específicas como la pregunta o el abogado del diablo, pueden visualizarse opciones que el mediador logra proponer sin perder por ello su neutralidad.

Por otro lado, su carácter confidencial ayuda a la empresa a no desprestigiarse en el mercado en el que funciona. Este tema reviste mayor importancia cuanto más pequeño es ese mercado, como en el caso de Uruguay, en donde el impacto negativo a nivel reputacional por ingresar a un proceso concursal es alto.

Sin perjuicio de que la personalidad es una de las características de toda mediación, en el ámbito comercial debe abordarse con un enfoque más amplio, ya que es práctica usual que las empresas cuenten con representantes para este tipo de instancias. Lo que sí es estrictamente necesario es que quien comparece a la mediación debe tener capacidad de toma de decisión, al igual que sucede con el representante de la empresa en una junta de acreedores.

La mediación también es un proceso flexible e informal, es decir, no tiene una estructura rígida que necesariamente deba ser cumplida, sino que es adaptable a cada situación en el marco de ciertas reglas de conducta y buena fe.

Un acuerdo alcanzado en este ámbito estaría libre de los requisitos legales que se exigen en un convenio concursal en cuanto a plazos de presentación, documentos que deben acompañar la propuesta y, principalmente, de etapas de consideración y voto. A su vez, permitiría dar continuidad y evitar la paralización del proceso hasta la realización de la junta de acreedores.

La accesibilidad es una característica del método que es valorada en muchos ámbitos, ya que los costos que genera una solución judicial pueden desmotivar al deudor a recurrir a ella. La mediación, por ser un proceso flexible, con bajos costos y mayor rapidez, genera una accesibilidad indiscutible y se convierte esta en una de las grandes ventajas a la hora de ser utilizada frente al proceso judicial. Asimismo, y desde la perspectiva de los acreedores, un proceso flexible que fomenta la posibilidad de negociar los términos de un acuerdo e intervenir en su redacción puede motivarlos a participar. 
Por último, tiene como finalidad visualizar el futuro y no mirar hacia el pasado; no se buscan culpables, sino gestionar el conflicto desde el presente y mirando hacia adelante, generando menos desgaste en los vínculos entre las partes. No hay pocos casos en que el acreedor, al verse defraudado por su deudor, prefiere que este sea liquidado antes que recuperar su crédito. La mediación permite, en tales circunstancias, mejorar el vínculo - por esta mirada a futuro-, promueve el diálogo sin tomar en cuenta los motivos que llevaron al deudor al estado de insolvencia y pone el foco en buscar una solución consensuada.

Leopoldo Pons manifiesta que «se puede afirmar que la inmensa mayoría de las situaciones reales de insolvencia no pasan nunca por un tratamiento judicial adecuado» (2015, pp. 41 - 43). Esto genera que los conflictos, muchas veces, no queden resueltos de una manera eficiente dentro del proceso concursal y ninguna de las partes que intervienen quede satisfecha. De ahí la importancia de implementar un nuevo método de resolución alternativa que trate en forma adecuada el conflicto instalado.

\section{El rol del mediador concursal}

Tal como hemos expuesto, el mediador es la persona que asiste a las partes en el proceso, es imparcial, neutro, no es juez ni árbitro, no opina y no sugiere la solución al conflicto, sino que conduce a las partes al desarrollo de la comunicación para que ellas mismas, asistidas por sus asesores legales, puedan encontrar una solución acorde a sus intereses y posiciones. El mediador debe cumplir con las características fundamentales de su rol, que son la neutralidad, la imparcialidad y la confidencialidad.

En el proceso concursal, el mediador ha de gestionar una situación en la que el conflicto es la falta de pago de los créditos por parte de un deudor a sus acreedores por la insuficiencia de recursos económicos. Si bien podríamos afirmar que el conflicto que abordará el mediador, en principio, es este, no es el único que puede plantearse, ya que - en la mayoría de los casos - ha pasado mucho tiempo como para que los diversos actores sigan formando parte de un proceso concursal y, mientras tanto, pueden haber acaecido muchos otros acontecimientos que generan conflictos colaterales. Estos pueden perjudicar, sobre todo, la relación del acreedor con sus deudores y pueden llegar a poner en riesgo la viabilidad de la empresa. Pese a denominarlos conflictos colaterales, no dejan de revestir mucha importancia $\mathrm{y}$, seguramente, el mediador deba comenzar a trabajar sobre ellos para mejorar el vínculo, para — luego - gestionar el conflicto principal (Ortiz, 
2015 , pp. 18 -23). Es oportuno agregar que al gestionar el conflicto dentro del proceso concursal pueden surgir discrepancias internas en la propia empresa, las que también deberá gestionar el mediador, ya que estas pueden impactar directamente en el desarrollo del proceso principal.

La importancia del rol del mediador se centra en la tarea que desarrolla. En aquellos países en donde el tema está legislado, radica en el trabajo constante de gestión del conflicto que realiza durante los plazos que deben cumplirse.

En primer lugar, el mediador debe analizar el conflicto a tratar, evaluar la viabilidad de la empresa y realizar un análisis de los créditos y de su posible calificación para poder prever quiénes serán los eventuales acreedores que formarán parte del proceso.

En algunas ocasiones, el método requerirá que el mediador realice sesiones privadas con uno o más representantes de la empresa a los efectos de compartir la información obtenida, evaluar las causas que la han llevado a esta situación, recabar su opinión sobre la empresa en la actualidad, diagnosticar si existiesen otro tipo de conflictos, entre otros fines.

Una vez analizado esto, deberá evaluar la existencia de los ya mencionados conflictos colaterales que impidan el normal funcionamiento de la empresa: conflictos entre los socios — en caso de tratarse de una empresa familiar, además se suman los conflictos personales - y aquellos que suceden dentro del directorio de la empresa. Estos problemas, seguramente, deban ser gestionados en forma previa para seguir adelante con la mediación.

En esta etapa, el mediador puede, a través de la aplicación de las técnicas, gestionar la comunicación entre las partes y lograr que estas alcancen miniacuerdos o acuerdos parciales en los que se reflejen cambios en la directiva, el nombramiento de gestores independientes a la empresa o la elaboración de protocolos familiares, si fuese necesario, según el tipo de empresa.

Habiendo estudiado toda la documentación y establecido el mapa del conflicto, se puede:

(i) generar una sesión conjunta o

(ii) comenzar con sesiones privadas con acreedores para conocer, más allá de su posición dentro del proceso, su posible interés en este. No es necesario reunirse con todos los acreedores; será el mediador quien deberá seleccionar con qué 
acreedores tiene interés en mantener sesiones individuales, sin perder de vista la incidencia que tienen a la hora de obtener una mayoría para aprobar un convenio.

El mediador concursal debe asegurarse de la legitimidad de quienes intervienen en el proceso y contar con su buena fe, principio básico del proceso de mediación que debe ser respetado tanto por las partes como por el mediador, desde el principio hasta el final. Dicha legitimación se consigue con el trabajo del mediador a través de sus herramientas, para lograr que el propio deudor sea quien legitime a los acreedores, reconozca el daño que ha generado y se responsabilice.

Por otro lado, el mediador debe generar un ambiente de confianza en el que los acreedores se sientan cómodos para poder plantear sus inquietudes y compartir información sobre las concesiones logradas en la etapa anterior, que tornan viable el alcance de un acuerdo que satisfaga los intereses de todas las partes. Es fundamental que el mediador, en esta etapa, consiga mover a las partes de sus posiciones a sus intereses; trabajo que ya había comenzado en las sesiones privadas con cada una de ellas.

En la etapa siguiente, el mediador debe lograr generar y evaluar propuestas, en el marco normativo en el que esté trabajando, en cuanto a plazo y posibles soluciones. La tarea, entonces, se centrará en el uso de las herramientas oportunas a los efectos de lograr que, a través de una comunicación efectiva entre el deudor y los acreedores, estos puedan proponer alternativas, sin comprometer la viabilidad de las empresas. Lo fundamental en esta etapa es el trabajo del mediador en cuanto a mantener el equilibrio de las partes y ayudarlas acercarse a un consenso.

Si las partes, con el apoyo del mediador, logran un acuerdo, seguramente, este tenga éxito en su cumplimiento, ya que existió compromiso de todos los involucrados en su elaboración, todos satisficieron sus intereses y, además, los vínculos, indudablemente, saldrán fortalecidos con miras a poder mantener las relaciones comerciales (Ortiz, 2015, pp. $18-23)$.

No es posible dejar de lado el análisis en este punto de la necesaria formación del mediador para poder ejercer su tarea en forma profesional. La doctrina está dividida al respecto de si es necesaria, además de una formación especial en la gestión alternativa de conflictos, una formación específica en el ámbito del conflicto en el que se está mediando. Nieva Fenoll (2014) manifiesta que: 
El mediador debe tener conocimientos profundos de Derecho para poder acompañar a las partes en la consecución de la mediación, así como conocimientos psicológicos a nivel de postgraduado que le permitan la adquisición de esas habilidades y competencias propias de la persuasión. (p. 734.)

Es atendible lo expresado por el autor en ciertos conflictos en los que el acuerdo al que se arriba requiere determinados requisitos jurídicos, como, por ejemplo, el acuerdo extrajudicial de pagos en el ámbito de un proceso de mediación concursal. Sin perjuicio de que la asistencia letrada sea obligatoria en Uruguay, de acuerdo a lo mencionado anteriormente, coincidimos en que la formación de origen con cierta especificidad en la materia —en este ámbito— puede ser relevante.

Esta necesaria formación debe ir acompañada para quien ejerza la tarea de una recompensa salarial adecuada, ya que esta ha sido una de las causas, según la doctrina y jurisprudencia española, de la falta de aplicación del mecanismo en ese país. El hecho de que el pago del mediador esté condicionado al proceso genera situaciones en las que el profesional no cobra su remuneración. Este hecho ha provocado en España que muchos mediadores profesionales se retiren del registro correspondiente, ya que no les es rentable la tarea en este ámbito bajo esas condiciones (Perea, 2020, p. 8).

Una de las desventajas que, entendemos, deberá afrontar la figura del mediador concursal es el hecho de que, si bien en Uruguay la mediación está alcanzando mayor protagonismo como método alternativo de solución de controversias, las personas lo desconocen o desconfían de los resultados que se pudieran obtener por esta vía. En México, a modo de ejemplo, se ha salvado esta situación a través de la incorporación de la mediación al ordenamiento jurídico de los diferentes Estados (Carretero, 2017, .58 59). En Uruguay, a nuestro entender, se debería legislar la figura del mediador para dar más fuerza a este método alternativo que permitirá brindar resultados óptimos.

\section{Derecho comparado}

\section{Según manifiestan Boronat y Ruiz (2015):}

En Europa se estableció la mediación a través de la Directiva 2008/52/CE, que venía a regular ciertos aspectos de la mediación en asuntos civiles y mercantiles, si bien, en España, y a través de la Ley 5/2012, se introducen 
dichas dos categorías y se integran dichas áreas junto a la mediación familiar y la mediación penitenciaria [...] (p. 25.)

Adentrándonos en la mediación mercantil en Europa, los mismos autores sostienen:

En el caso de Portugal, se dispone de un órgano administrativo centralizado encargado de la regulación de las actividades de mediación pública, la Dirección General de Política de Justicia, sin embargo, y aun faltando un código de conducta nacional para los mediadores, la mediación en materia familiar, laboral y penal tiene sus propias estructuras y cuenta con mediadores especializados, mientras que la mediación civil y mercantil se produce en el marco de un proceso judicial ante los juzgados de paz. (p.

De lo anterior se infiere que, a nivel público, la Dirección General de Política de Justicia (Direção Geral da Política de Justiça, s. f.) prevé en forma expresa la aplicación de la mediación en el ámbito familiar, laboral y penal. Sin perjuicio de ello, la mediación civil podrá aplicarse no solamente para los asuntos que se llevan a cabo en los Juzgados de Paz, sino, también, en aquellos asuntos que no están circunscriptos a su jurisdicción, como en el caso de los asuntos mercantiles o concursales.

El autor José Guillermo Cuadra Ramírez (s. f., p. 19), por su parte, indica que, a través de la mediación y otros métodos alternativos de solución de controversias, en Portugal pueden gestionarse todos los conflictos, con excepción de aquellos que tengan por asunto derechos indisponibles, es decir, aquellos que no pudieren renunciarse.

Continúan Boronat y Ruiz (2015):

En el caso de Alemania, el 26 de julio de 2012 entró en vigor la Ley sobre la mediación (Ley de fomento de la mediación y otros procedimientos de resolución extrajudicial de litigios). Se trata de la primera norma jurídica que regula formalmente los servicios de mediación en ese país, al mismo tiempo que incorpora asimismo al ordenamiento jurídico alemán la Directiva Europea sobre mediación (Directiva 2008/52/CE) y con arreglo a esa norma, los mediadores son personas independientes e imparciales, sin poder decisorio, que guían a las partes interesadas en el procedimiento de mediación. (p. 29.) 
Álvaro Pérez Ragone (2013) manifiesta, en cuanto al espíritu de la legislación vigente en Alemania, que «el deudor debe haber agotado todas las posibilidades de solución extrajudicial de deudas y el juez del concurso decide en última instancia aprobar o no el procedimiento y planes en caso de insolvencia» (p. 669). Dicho procedimiento extrajudicial, según lo que establece la normativa alemana vigente, resulta aplicable con carácter obligatorio a los consumidores y a los empresarios de media o reducida dimensión, pero se limita el número de acreedores del deudor, que no pueden ser más de veinte.

En el caso de Italia, han sido varias las modificaciones en relación con la mediación en el ámbito mercantil. El Decreto Legislativo 28/2010 introdujo en el país el sistema de mediación civil y mercantil, estableciendo la obligatoriedad de este método de resolución alternativa de controversias. En el año 2013, a través de una nueva modificación, se restableció la obligatoriedad de la mediación con ciertas condicionantes - obligatoriedad que había sido suprimida por la Corte Constitucional en el año 2012como un requisito previo a entablar una demanda judicial. Asimismo, se contemplaron otros aspectos tales como la competencia territorial, régimen de retribución de los organismos de mediación, asistencia legal obligatoria, y se incorporaron nuevas materias para resolver a través de este método. A su vez, para dar vigor a la obligatoriedad, se admitió como excepción de improcedibilidad del proceso la falta de citación a mediación (Cavuoto, 2014). La más reciente modificación se produjo el 12 de enero de 2019, referente a la reforma del régimen de la insolvencia, y brinda al legislador la posibilidad de crear un organismo nuevo, el OCRI (Organismo di Composizione della Crisi d'Impresa). Así se busca ofrecer soluciones ajustadas a las características de los operadores económicos y que los administradores de la insolvencia se encuentren más próximos a los deudores y acreedores cuya situación habrán de gerenciar. Sobre esto, Laura Chalar (2019) manifiesta:

Este novedoso organismo ha sido dotado de facultades para la aplicación de un método de resolución alternativa de controversias, acercando a las partes y poniendo su experticia y la información de que dispone al servicio de la búsqueda de una solución temporánea y eficiente, lograda en una etapa temprana de la crisis. (p. 70.)

Respecto de España, Boronat y Ruiz (2015) explican: 
En España, como vemos, se ha establecido un margen muy distinto a la mediación, dotándola de un texto marco para los asuntos civiles y mercantiles, regulando los aspectos familiares mediante regulación específica en cuatro comunidades autónomas y, además, regulando la mediación mercantil.

Esta puesta final de la mediación, incluso en el proceso concursal, es a través de las modificaciones realizadas en la Ley Concursal (en adelante, LC) por medio de la Ley 14/2013. [...]

En este sentido, el mediador concursal, con requisitos de acceso al recién formado Registro de Mediadores Concursales, de acuerdo con la experiencia y antigüedad colegial del administrador concursal, se configura como un nuevo profesional que acaba siendo la figura central del proceso preconcursal de negociación y en su caso, del proceso del AEP. (p. 29.)

En relación con los requisitos que debe reunir el mediador concursal en España, se ha señalado que, si bien puede ser mediador cualquier persona física o jurídica con formación en materia de mediación, deberá, además, contar con una especialización en materia mercantil. Isabel Candelario señala, incluso, la obligatoriedad para el mediador concursal de obtener un seguro de responsabilidad civil o garantía, atendiendo a la importancia de la labor que realiza en sede preconcursal $(2015$, p. 57).

Por su parte, en Brasil, en este momento — dada la situación de crisis actual—, está en las cámaras un proyecto de ley que crea la mediación obligatoria previa al proceso judicial. Esto quiere decir que un deudor en estado de insolvencia debe pasar por un proceso de mediación antes de recurrir al ámbito judicial. ${ }^{3}$

Juana Pulgar (1994, p. 28) manifiesta que todo el movimiento de reforma legislativo, en el cual incluye a Brasil, apunta a generar procesos que incentiven la conservación de la empresa viable como única causal que justifica el sacrificio del acreedor. Se prevén, en los países mencionados, procesos organizativos en los que se

\footnotetext{
${ }^{3}$ El proyecto de ley de la Cámara de Senadores 4458 de 2020 en Brasil manifiesta en su artículo 22, numeral $\mathrm{J}$ : «Estimular, sempre que possível, a conciliação, a mediação e outros métodos alternativos de solução de conflitos relacionados à recuperação judicial e à falência, respeitados os direitos de terceiros, na forma do $3^{\circ}$ do art. $3^{\circ}$ da Lei $n^{\circ} 13.105$, de 16 de março de 2015(Código de Processo Civil)». El artículo de la ley citada establece que «a conciliação, a mediação e outros métodos de solução consensual de conflitos deverão ser estimulados por juízes, advogados, defensores públicos e membros do Ministério Público, inclusive no curso do processo judicial».
} 
logre transformar el conflicto de insolvencia y obtener la viabilidad de la empresa y la satisfacción del crédito de los acreedores.

A modo de resumen, podemos decir que en el ámbito internacional la mediación mercantil o concursal se aplica desde hace muchísimos años. Dependiendo del país, se puede ver aplicada como un método preconcursal de carácter obligatorio; en otras ocasiones, como parte del mismo proceso concursal o como una gestión extrajudicial. Además, la figura del mediador puede estar compuesta tanto por un individuo - mediador profesional con formación en la materia y registrado ante el organismo que los regulacomo por una entidad creada específicamente para la gestión de conflictos, compuesta por mediadores con experiencia en la materia.

En Estados Unidos, según Ariel Dasso (2018), en el actual Bankruptcy Code «se encuentran regulados todos los procedimientos concursales del sistema norteamericano, que pone a disposición de los interesados diferentes alternativas para la reorganización de sus crisis económico-financieras» (p. 210). El autor manifiesta que a través de esta regulación se «ha puesto en marcha un nuevo paradigma, que podríamos llamar “conservacionista", poniendo además el énfasis en que la empresa sea “viable”» (p. 230).

Héctor Miguens (2018, pp. 231 - 281) afirma que en ese país, en el momento en que la empresa se encuentra en estado de insolvencia, cuenta con dos opciones: liquidar sus bienes a los efectos de satisfacer el crédito a sus acreedores con lo producido o acudir a procedimientos extrajudiciales que le permitan superar ese estado en el que se encuentra; son los llamados Consensual Restructurings, Out-of-Court restructurings o, también, Workouts, Extensions o Compositions.

Este instrumento - la mediación - consiste en un acuerdo extrajudicial logrado entre el deudor y sus acreedores a través de profesionales que interceden en dichas negociaciones que pueden ser contadores, abogados o facilitadores.

Asimismo, no es menor recordar los grandes resultados que se han obtenido a nivel internacional por la utilización de la mediación, tal como destaca Chalar (2019), particularmente en Estados Unidos:

Un ejemplo de caso de alto perfil donde la mediación fue empleada con éxito es el de la falencia de Lehman Brothers, donde se previno mediante este método un sinnúmero de acciones individuales y se recuperaron, de esta forma, cerca de dos mil millones de dólares para la masa. (p. 67.) 
Por todo lo anterior, estando a los resultados que la mediación concursal ha tenido en derecho comparado en cuanto a eficacia, menores costes y subsistencia del método, que cada día gana mayor obligatoriedad en su aplicación para evitar o resolver conflictos, es que consideramos que la introducción del rol del mediador concursal en Uruguay es fundamental.

\section{Análisis del proyecto de ley que crea la figura del mediador concursal en Uruguay}

\section{Comentarios generales sobre el proyecto de ley presentado}

En 2020, la Asociación Uruguaya de Peritos presentó un Proyecto de Ley (en adelante, el Proyecto) a los efectos de modificar ciertas disposiciones de la Ley vigente (Proyecto de Ley, Comisión de Constitución, Códigos, Legislación General y Administración de la Cámara de Diputados, 2020). Dentro de estas modificaciones, se comprende la posibilidad de que la empresa que se encuentra en estado de insolvencia dé cuenta a la sede judicial a efectos de poder iniciar negociaciones con sus acreedores y que se designe, en consecuencia, un mediador concursal que ayudará a gestionar el conflicto dentro de un plazo de noventa días, en el que podrá suscribirse un acuerdo privado de reorganización. De no alcanzarse, el juez declarará el concurso.

Con esta previsión, el juez le concedería a la empresa deudora la moratoria provisional que impedirá que sus acreedores soliciten la declaración de su concurso, promuevan medidas cautelares o ejecuciones sobre los bienes y derechos que forman parte del patrimonio del deudor, y quedan en suspenso aquellas que ya hubieren sido iniciadas. Se suspende, asimismo, la obligación impuesta al deudor de solicitar su propio concurso a los treinta días de constatada la situación de insolvencia.

Tal como fue mencionado, dentro de las innovaciones de este Proyecto se crea la figura del mediador concursal para llevar adelante la negociación entre deudor y acreedores. En la exposición de motivos se plantea que:

La figura del mediador concursal difiere en sus facultades, funciones y objetivos de la del síndico o interventor concursales. Por un lado, el mediador ni suplanta ni supervisa al deudor en la administración de su patrimonio, quien conserva a lo largo de toda la negociación la plena legitimación para disponer de sus bienes, derechos y obligaciones. Por otro 
lado, el mediador, a diferencia del síndico y el interventor concursales, ejerce un papel activo en la consecución del acuerdo privado de reorganización, promoviendo el acercamiento de las partes y asesorando al deudor y a sus acreedores. Esta función de promoción de la negociación resulta especialmente necesaria en las crisis económicas de pequeños y medianos emprendimientos, en los que los deudores y acreedores no suelen ser agentes sofisticados ni tienen acceso a un asesoramiento jurídico y económico especializado. (Proyecto de Ley, Comisión de Constitución, Códigos, Legislación General y Administración de la Cámara de Diputados, 2020.)

En el Proyecto se prevé, asimismo, el procedimiento para la asunción del cargo de mediador, las condiciones del ejercicio de su actividad, las incompatibilidades del cargo y el régimen de responsabilidad que replican las disposiciones ya previstas en la Ley para síndicos e interventores.

\section{Diferencias entre el rol del mediador y el síndico en el proceso concursal}

Sin perjuicio de lo anterior, corresponde destacar, como diferencia fundamental entre las figuras del mediador concursal y la de síndicos e interventores, que el rol del mediador estará en el acercamiento de las partes — deudor y acreedores — para negociar y tratar de obtener un resultado favorable, sobre todo, para pequeñas y medianas empresas - tanto concursadas como acreedoras-, que podrán suscribir un acuerdo privado de reorganización en el que todos los involucrados puedan ganar - ganar. Por otro lado, el acercamiento de las partes para alcanzar un acuerdo excede el rol de síndicos e interventores, que están limitados, únicamente, a un análisis de viabilidad y legalidad de la propuesta —si es que esta existe- y, eventualmente, valorarán si existió responsabilidad del deudor, para lo que calificarán su conducta previa al estado de insolvencia.

En definitiva, la propuesta de incorporar legalmente la figura del mediador concursal en la Ley nos parece fundamental a los efectos de poder llegar a acuerdos en los que todas las partes del proceso puedan resultar beneficiadas, para acortar los plazos judiciales y los costos asociados y permitir también al derecho concursal uruguayo aggiornarse a las tendencias internacionales. 


\section{Conclusiones}

Ante la variación producida por los ciclos de la economía, la legislación vigente resulta insuficiente para afrontar adecuadamente los escenarios de insolvencia empresarial. La realidad judicial actual, así como la escasa tasa de recuperación del crédito por parte de los acreedores, demuestran que una empresa que ingresa a un proceso concursal difícilmente logra su continuidad. Por ello, se torna necesaria la búsqueda de métodos alternativos para intentar obtener mejores resultados que los actuales.

Entendemos que la mediación como método de resolución alternativa de conflictos aplicada al ámbito de las relaciones empresariales y, puntualmente, sobre el concurso de acreedores permitirá alcanzar mejores soluciones. Estas podrán lograrse más rápidamente que a través de un proceso puramente judicial, que debe, necesariamente, transitar por estructuras y plazos rígidamente establecidos. Podrán alcanzarse dichas soluciones a un costo menor, no solamente en cuanto a las costas y costos que implica un proceso, sino en la reducción de la pérdida de valor en la economía de la empresa insolvente. Permitirá, asimismo, la preservación de las relaciones comerciales, motivada por la posibilidad de adopción de soluciones consensuadas en vez de impuestas, al brindar instancias de negociación entre deudores y acreedores de forma más personal y directa, en lugar de la escasa participación demostrada a la luz de la normativa vigente.

Resulta trascendente que quien cumpla el rol de mediador cuente con formación en el ámbito de la gestión alternativa de conflictos. Por otra parte, dependiendo del conflicto que haya que gestionar, se deberá evaluar la necesidad de una formación de origen.

La inclusión de la figura del mediador en el ámbito del derecho concursal no haría más que acompañar la tendencia mundial según la cual la consideración de soluciones no adversariales, por su probado éxito, va ganando terreno. Es el deber de todos los operadores del derecho discutir la posibilidad de incorporar a la normativa vigente esta clase de soluciones, a efectos de no quedar constreñidos en institutos que requieren de constante actualización y modernización para resultar confiables y eficaces para las partes intervinientes. 


\section{Referencias}

Balletto, S., Briz, M. y Falca, L. (2015). Manual básico de Mediación. Universidad Católica del Uruguay.

Boronat, G. y Ruiz, D. (2015). Mediación mercantil: alternativa jurídica para las empresas. Estrategia Financiera, (329), 25 - 26.

Bove, M. (2011). La conciliazione nel sistema dei mezzi di risoluzione delle controversia civil. Rivista trimestrale di diritto e procedura civile, 65(1), 125 - 158.

Candelario, M. (2015). El mediador concursal. Tirant Lo Blanch.

Carretero, E. (2017). La adecuación de la mediación y los métodos alternos de solución de controversias como instrumentos para la salvaguarda de los derechos. Revista del Centro Nacional de Derechos Humanos, (30), 58 - 59.

Cavuoto, E. (2014). La nueva mediación obligatoria en Italia. Revista General de Derecho Procesal, 34. https://www.iustel.com/v2/revistas/detalle_revista.asp?id_noticia=415017\&d=1

Chalar, L. (2019). Mediación en el concurso: El ejemplo italiano, en El derecho comercial en el camino de revisión de la normativa societaria y concursal (pp. 65-70). Fundación de Cultura Universitaria.

Código General del Proceso. Ley Procesal Civil 16.995 de 1998, artículo 2 (Uruguay). Recuperado el 16/10/2020 de https://www.impo.com.uy/bases/leyes/16995-1998/2

Cuadra Ramírez, J. G. (s. f.). Medios alternativos de resolución de conflictos como solución complementaria de administración de justicia. https://www.scjn.gob.mx/sites/default/files/transparencia/documentos/becarios/040joseguillermo-cuadra-ramirez.pdf

Dasso, A. (2018). Código de Bancarrotas de los Estados Unidos. Un comentario de aproximación. Revista Informática de Derecho del Instituto Iberoamericano de Derecho Concursal, 10(2), 209 - 231. https://revistas.unc.edu.ar/index.php/esdeem/issue/view/1407

Direção Geral da Política de Justiça. (s. f.). Alternative Dispute Resolution. https://dgpj.justica.gov.pt/English/Alternative-Dispute-Resolution\#Mediation

Dueñas, D. (2017). Alternative Dispute Resolution in Business. Anuario de Justicia Alternativa, (14), $99-108$.

Folberg, J. y Taylor, A. (1997). Mediación: resolución de conflictos sin litigio. Grupo Noriega Editores - Limusa.

Highton, E. y Álvarez, G. (2004). Mediación para resolver conflictos. Ad Hoc.

Martínez, C. (2018). Manual de Derecho Concursal. Fundación de Cultura Universitaria. 
Miguens, H. (2018). El proceso concursal extrajudicial previo en el Código de Quiebras de Estados Unidos (el «Prepackaged Chapter Eleven» del U.S. Code). Díkaion, 27(2), 231 -281 .

Nieva Fenoll, J. (2014). La ciencia jurisdiccional: novedad y tradición. Marcial Pons.

Olivera, R. (2008). Principios y bases de la nueva Ley de Concursos y Reorganización Empresarial. Fundación de Cultura Universitaria.

Ortiz, A. (2015). Mediación concursal, una visión positiva. Estrategia Financiera, (329), 18 23.

Perea, Á. (2020). Diálogos para el futuro judicial x. El mediador concursal. Diario La Ley, (9707).

Pérez Ragone, Á. (2013). La progresiva humanización de los procesos de insolvencia de personas naturales: desde la servidumbre e infamia hasta los procesos concursales de consumidores. Revista de Derecho de la Pontificia Universidad Católica de Valparaíso, (41), 641 - 678.

Pons, L. (2015). El nuevo modelo concursal, tras la reforma 2014, debería ser más flexible con la empresa familiar. Estrategia Financiera, (323), 41 - 43.

Proyecto de ley Declaración Judicial de Concurso y Reorganización Empresarial: se modifican disposiciones a la Ley 18.837, Repartido 147 (2020). Comisión de Constitución, Códigos, Legislación General y Administración de la Cámara de Diputados, Uruguay. https://legislativo.parlamento.gub.uy/temporales/R01476505183.pdf

Pulgar, J. (1994). La reforma del derecho concursal comparado y español: los nuevos institutos concursales y reorganizativos. Editorial Civitas.

Sánchez, A. (2018). La mediación en el acuerdo extrajudicial de pagos (Tesis de doctorado). Universitat Rovira i Virgili, Tarragona, España. https://www.tdx.cat/bitstream/handle/10803/668394/TESI.pdf?sequence=1\&isAllowed $=\mathrm{y}$

Taruffo, M. (2 - 3 de junio de 2011). Globalizing Procedural Justice. Some General Remarks, en Á. Pérez Cruz y X. Ferreiro (dirs.), Actas del iv Congreso Gallego de Derecho Procesal ( $i$ internacional) (pp. 17-29). La Coruña, España.

\section{Contribución autoral}

a) Concepción y diseño del trabajo; b) Adquisición de datos; c) Análisis e interpretación de datos; d) Redacción del manuscrito; e) revisión crítica del manuscrito.

M.J.B.C. ha contribuido en a, b, c, d, e; D.M.V.C. en a, b, c, d, e; F.R.M. en a, b, c, d, e.

\section{Editor científico responsable}

Dra. María Paula Garat 